\title{
Geometria de Distâncias e Geometria Molecular
}

\section{Andrês Rodrigues Oliveira*, Carlile Lavor.}

\section{Resumo}

Determinar formas eficientes de se calcular a estrutura 3D de uma molécula é um problema importante no setor farmacêutico. Uma das formas de fazê-lo é utilizar dados de distâncias entre os átomos, e após uma modelagem de dados, executar o algoritmo Branch \& Prune (BP). Usando o BP, podemos encontrar a estrutura molecular.

\section{Palavras-chave:}

Geometria, Estrutura Molecular, Branch \& Prune.

\section{Introdução}

A funcionalidade de uma molécula está relacionada com sua estrutura 3D. Determinar, então, seu formato é importante para bioquímicos e farmacêuticos. Uma das maneiras de fazer isso é usar dados das distâncias conhecidas entre os átomos das moléculas, distâncias estas vindas de experimentos de Ressonância Magnética Nuclear (RMN) ${ }^{1}$. Utilizar os dados dessas distâncias para determinar a estrutura é conhecido como Molecular Distance Geometry Problem (MDGP) ${ }^{3}$.

\section{Resultados e Discussão}

Diferente dos métodos de otimização contínua, nossa proposta é trabalhar com o caráter combinatório do problema. Para isso, vamos modelar nosso problema como um grafo $G=(V, E, d)$, onde os vértices $V$ são os átomos, as arestas $\mathrm{E}$ e a função $d: E \rightarrow(0, \infty)$ representam as distâncias conhecidas. Queremos, então, associar a cada $v \in V$ um ponto no espaço $\mathrm{x}_{\mathrm{v}}$ tal que $\forall(u, v) \in E,\left\|x_{u}-x_{v}\right\|=d_{u, v} \quad{ }^{2}$

As distâncias entre pares de átomos separados por ligações covalentes são, devido a resultados provenientes da química, conhecidas de antemão². Sendo assim, conseguimos fixar os primeiros átomos da molécula, a fim de evitar soluções vindas de translações e rotações. Usando informações sobre a geometria molecular, é possível definir uma ordem entre os átomos da cadeia principal da molécula cuja estrutura 3D queremos calcular ${ }^{2}$. Estaremos em um caso específico do MDGP, o Discretizable Molecular Distance Geometry Problem (DMDGP) ${ }^{3}$. Para resolver o DMDGP, temos o algoritmo Branch \& Prune (BP ${ }^{4}$, cujo espaço de busca é uma árvore binária ${ }^{1}$, onde os três primeiros átomos são fixados, e, a partir do quarto vértice, temos duas opções para a realização no espaço 3D. As distâncias que conhecemos vindas da RMN ajudam a diminuir o espaço de busca "apontando" o caminho da solução".

A intuição do algoritmo é fazer intercessão de esferas. Para antes rodar o BP, precisamos de encontrar uma realização válida para os três primeiros vértices. A ordem em $V$ garante que após o quarto vértice, temos que todo vértice $v$ possui ao menos 3 distâncias conhecidas $d_{v-3, v}, d_{v-2, v}, d_{v-1, v}{ }^{4}$. Então se fizermos a intercessão de esferas com centros em

$x_{v-3}, X_{v-2}, X_{v-1}$, com raios as distâncias respectivas até $v$, teremos no máximo 2 realizações possíveis para esse vértice $v^{4}$.
Vejamos agora um caso de teste. As distâncias que conhecemos dela colocaremos em uma matriz(Figura 1), chamada de matriz de distâncias, onde a posição i,j representa a distância entre os vértices i e j. As soluções geradas pelo BP estão na figura 2.

Figura 1. Matriz de Distâncias

$\left[\begin{array}{ccccccc}0 & 1.526 & 2.49139 & 3.06432 & \infty & 3.11285 & \infty \\ 1.526 & 0 & 1.526 & 2.49139 & 2.89562 & \infty & \infty \\ 2.49139 & 1.526 & 0 & 1.526 & 2.49139 & 2.92387 & \infty \\ 3.06432 & 2.49139 & 1.526 & 0 & 1.526 & 2.49139 & 2.93805 \\ \infty & 2.89562 & 2.49139 & 1.526 & 0 & 1.526 & 2.49139 \\ 3.11285 & \infty & 2.92387 & 2.49139 & 1.526 & 0 & 1.526 \\ \infty & \infty & \infty & 2.93805 & 2.49139 & 1.526 & 0\end{array}\right]$

Figura 2. Soluções encontradas pelo BP
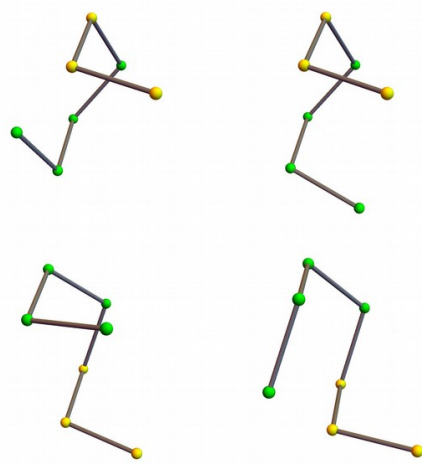

\section{Conclusão}

Apesar de o BP encontrar todas as soluções, ele o faz de maneira ingênua, percorrendo toda a árvore, elevando, assim, seu custo computacional. Dessa forma, o futuro do projeto visa estudar maneiras de otimizar essa busca, explorando as simetrias do DMDGP.

\section{Agradecimentos}

Agradeço ao $\mathrm{CNPq}$ pelo financiamento da pesquisa, modalidade Iniciação Científica - PICME, processo 124135/2018-8.

${ }^{1}$ LAVOR, C.; LIBERTI, L. Um Convite à Geometria de Distâncias. São Carlos: SBMAC, 2014.

${ }^{2}$ LAVOR, C. et al. Álgebra e Geometria no Cálculo de Estrutura Molecular. Rio de Janeiro: IMPA, 2017.

${ }^{3}$ LAVOR, C. et al. An Introduction to Distance Geometry applied to Molecular Geometry. New York: Springer, 2017.

${ }^{4}$ LIBERTI, L. et al. Euclidean distance geometry and applications. SIAM Review, v. 56, p. 3-6, 2014. 